\title{
斜面安定における三次元効果 \\ THREE DIMENSIONAL EFFECTS ON SLOPE STABILITY
}

\author{
菊 沢正 裕* \\ By Masahiro KIKUSA WA
}

\begin{abstract}
Numerous methods of three-dimensional (3-D) stability analysis have been proposed based on the limit equilibrium by the use of a cylindrical slip surface with various shape of caps. Herein we consider the mechanism that produces the 3-D effects by a variational stability analysis, in which a log-spiral slip surface is provided. From the numerical results, it is shown that 3-D effects are caused on account of the soil mass not moving to the steepest direction on the slip surface for a moderate slope of small friction, while 3-D effects are caused mainly by the end-effects for a steep slope of frictional material. It is noticed that $3-\mathrm{D}$ effects fail to be evaluated properly by the cylindrical surface for a moderate slope with small friction.

Keywords: safety factor, stability analysis, slope stability, slip surface
\end{abstract}

\section{1. 序}

従来提案されている三次元 (3D) 安定解析法の多く は円形すべりスライス法の三次元への拡張であり円錐あ るいは楕円キャップをもつ円筒面すべりを考えるもので ある.まず粘性土地盤を扱ったものとして Baligh ら ${ }^{11}$ は円筒面に円錐や楕円キャップを付加したすべり面に対 して三次元に拡張した簡便法によって計算される安全率 はすべり面の軸方向長さ, および土質強度に敏感であり, キャップ長も崩壊事例のそれより長くなることを指摘し ている. Ugai ${ }^{71}$ は変分理論を用いた解析の中で円筒, キャップ, 円形端面の 3 部分からなるすべり面を用い, キャップ形状が安定に及ぼす影響を検討している. Gens ら ( $^{3)}$ 斜面内, 斜面先および基礎の 3 つのすべり モードを考慮しつつ端部効果を多くの理論結果から評価 し, 既存の崩壊データを整理している. 特に理論解析で は端部を高次べき関数で評価した場合に臨界すべり面が 得られることを示した。一方，c- $\phi$ 斜面については Hovland $^{4)}$ がすべり面上に作用する垂直応力の方向性を 考慮した解析により $3 \mathrm{D}$ 解析の重要性を指摘している. さらに，スライスに作用する側方拘束力を考慮した

* 正会員 農博 京都大学助手 農学部農業工学科 ( ₹606 京都市左京区北白川追分町)
Chen ら, 鵜飼らの研究がある. Chen ら ${ }^{21}$ は二次元 Spencer 法を三次元に拡張した解析により緩い粘性土系 斜面では, 間隙圧を考慮した場合に $3 \mathrm{D}$ 効果が強くなる ことを示した。鵜飼ら ${ }^{81}$ は簡便分割法を三次元に拡張し， 側方拘束力効果を含めた $3 \mathrm{D}$ 安定評価と逆算問題の計算 例を与えている.

従来研究の多くは円筒+キャップ型すべり面を用い, キャップの形状効果やすべり面幅について検討している ものの, 円筒長とキャップ長の割合を予渆できるものが 少ない。しかし，斜面勾配や材料特性によってキャップ 部がどの程度になるかは重要である。円筒部と違い キャップ部では, 滑動方向とすべり面の最大傾斜方向が 異なることによって $3 \mathrm{D}$ 効果が強く現われると考えら れ, 滑動方向を一定亡する従来の方法では不十分と思わ れる. そこで, すべり面と滑動方向を合理的に決定でき る対数らせんすべり解析によって $3 \mathrm{D}$ 効果を検討した.

\section{2. 三次元効果を生じる原因}

Fig. 1 は一般に解析に用いられる三次元すべりの模式 図である. キャップとよばれる $\mathrm{S}_{2}$ の部分が平面の場合, $\mathrm{S}_{2}$ 部分には滑動力は働かずせん断抵抗力だけが作用す るため $2 \mathrm{D}$ 解析の安全率 $F_{2}$ に比へ， $3 \mathrm{D}$ 解析の安全率 $F_{3}$ の方が大きくなることは予想できる. よって, 三次 


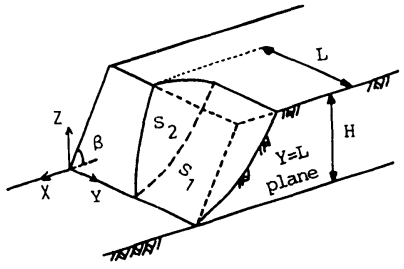

Fig. 1 Cylindrical slip surface with a cap.

元状態の臨界すべり面は， $\mathrm{S}_{2}$ 部分の抵抗を小さくする (つまり浅いすべりを要求する) 条件と $\mathrm{S}_{1}$ 部分のすべ り安全率 $\left(F_{2}\right.$ に対応する) をできるだけ小さくする条 件の両面から決まると考えられる．また $\mathrm{S}_{2}$ 部分が棈円 体など立体になると $\mathrm{S}_{2}$ 部分にも自重による滑動力が作 用し問題はさらに複雑になる。、ずれにせよ， $F_{3}>F_{2}$ となることが多く, その原因はキャップ $\mathrm{S}_{2}$ の存在, つ まり端部効果によると考えるのが一般的である. 端部効 果という場合, 狭い意味ではキャップ部の抵抗力による 効果であり，広い意味ではキャップが存在することに よって主要部 ( $\mathrm{S}_{1}$ 部分) のすべり面深さが影響される 効果を含んでいる。ここでは両者を併せて端部効果とよ ふ..

ここで，すり鉢状のすべり面を考えてみよう．このす ベり面上に球体を乗せると球体は，その位置におけるす ベり面の最大傾斜方向 $s$ に向かって転がり落ちる.さ て，土が破壊しすべり土塊のつり合いを保てなくなった 場合の滑動方向 $m$ (ここでは $m$ が最大せん断力 $\boldsymbol{t}$ の作 用方向之一致すると考えている）は方向 $s$ と一致する とは限らない，2Dすべりでは一致すると考え，また Fig. 1 の円筒すべりでも $m$ と $s$ は一致することになる. しかし $m$ と $s$ が一致しないことが原因で $3 \mathrm{D}$ 効果を生

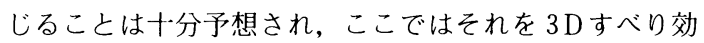
果とよぶことにする．ただし，3Dすべり効果が $3 \mathrm{D}$ 効 果にポジティブに作用するか否かについては不明であ る. 端部効果と $3 \mathrm{D}$ すべり効果は分離できないが, 滑動 方向が限定される円筒形すべりに対して，対数らせんす ベりは $3 \mathrm{D}$ すべり効果をある程度評価できると考える.

\section{3. 三次元効果に関する考察}

従来, Fig. 1 の記号による無次元パラメーター $L / H$ を用いてすべり面の特徴を表わして $3 \mathrm{D}$ 効果を評価する ことが多く, L/H が小さいほど $3 \mathrm{D}$ 効果が大きいとさ れている. Leshchinsky ら ${ }^{6}$ は円筒面と対数らせん面を 組み合わせたすべり面を用いて $L / H$ による $3 \mathrm{D}$ 効果を 計算し, 他の研究者の結果と比較している. それによる と斜面先すべりに限っていえば $3 \mathrm{D}$ 効果が強く現われる のは， $L / H \leqq 1.0$ の場合である．そこで，本研究では円 筒面を付加することなく対数らせんのみによる斜面先す
Table 1 Results of 2-D and 3-D variational stability analyses.

\begin{tabular}{ccccc}
\hline $\begin{array}{c}\text { slope } \\
\text { angle } \beta\end{array} \begin{array}{c}\text { friction } \\
\text { angle } \phi\end{array}$ & $\begin{array}{l}\text { 3D safety } \\
\text { factor } F_{3}\end{array}$ & $\begin{array}{l}\text { 2D safety } \\
\text { factor } F_{2}\end{array}$ & $\zeta=F_{3} / F_{2}$ \\
\hline $30^{\circ}$ & $0^{\circ}$ & 0.885 & 0.643 & 1.37 \\
& 5 & 1.176 & 0.935 & 1.26 \\
& 10 & 1.419 & 1.187 & 1.20 \\
& 20 & 1.932 & 1.667 & 1.16 \\
& 30 & 2.440 & 2.157 & 1.13 \\
\hline $45^{\circ}$ & $0^{\circ}$ & 0.800 & 0.587 & 1.36 \\
& 5 & 0.994 & 0.781 & 1.27 \\
& 10 & 1.170 & 0.952 & 1.23 \\
& 20 & 1.463 & 1.269 & 1.15 \\
& 30 & 1.830 & 1.609 & 1.14 \\
& 40 & 2.226 & 1.978 & 1.13 \\
\hline $75^{\circ}$ & $0^{\circ}$ & 0.585 & 0.457 & 1.28 \\
& 5 & 0.700 & 0.563 & 1.24 \\
& 10 & 0.800 & 0.655 & 1.22 \\
& 20 & 0.974 & 0.825 & 1.18 \\
& 30 & 1.152 & 0.994 & 1.16 \\
& 40 & 1.349 & 1.181 & 1.14 \\
\hline
\end{tabular}
$\zeta=F 3 / F 2$ : safety factor ratio
$\phi:$ angle of internal friction

$B$ :slope angle $\mathrm{c} / \mathrm{H}=0.1$

$\gamma$ :unit weight $H: s l o p e$ hight $c: c o h e s i o n$

$B=30^{\circ}$

$B=75^{\circ}$
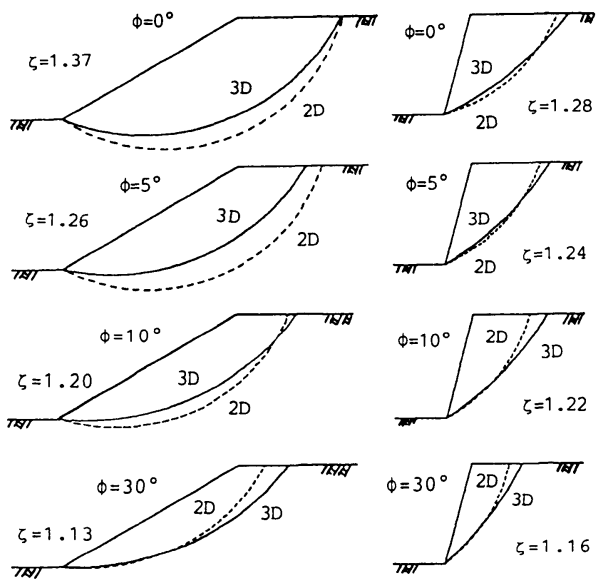

Fig. 2 Comparison between 2-D and 3-D analyses within $Y=$ $L$ plane (Fig. 1) of symmetrical slopes.

ベりに限定して 3 D 効果を評価することにし，Leshchinsky ら ${ }^{5}$ による変分安定理論に基づいた数值解析 コードを開発し, 典型的な斜面(安定数 $N=c / \gamma H=0.1$ ) に対する $2 \mathrm{D}$ および $3 \mathrm{D}$ 解析を行った.

Table 1 は種々の斜面傾斜角 $\beta$ と内部摩擦角 $\phi$ につい ての安全率比 $\zeta$ を示す.すべての斜面で $L / H$ は 1.0 前 後である. $3 \mathrm{D}$ 効果を表わすとが $\phi や \beta$ に影響されるこ とがうかがえる. Fig. 2 では, Fig. 1 の対称面 ( $Y=L$ 面) におけるすべり線を $2 \mathrm{D}$ 解析と $3 \mathrm{D}$ 解析によって求め比 較した. $3 \mathrm{D}$ 解析の結果得られたすべり線は $2 \mathrm{D}$ 解析の ものより浅くなっている場合が多く，前章で述べたよう に端部効果が現われている. しかし， $\beta$ が小さくても が大きい場合や， $\beta$ が $75^{\circ}$ といった急斜面では $2 \mathrm{D}$ の 


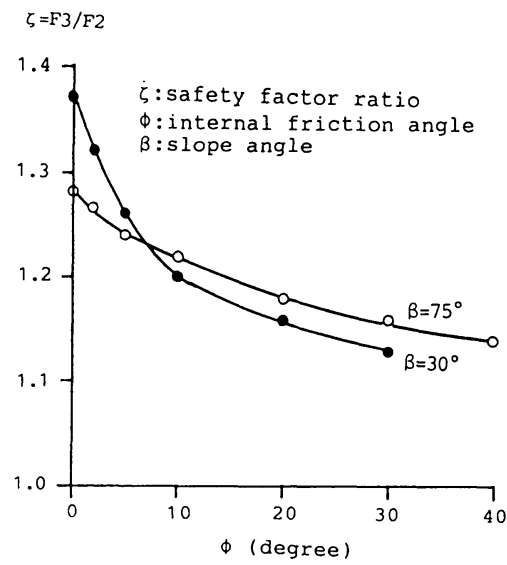

Fig. $3 \zeta \sim \phi$ relation.

ベり線が $3 \mathrm{D}$ のすべり線と同じか，ときに浅くなる現象 が認められ，3Dすべりの複雑さを物語っている.

Fig. 3 は, Table 1 に基づいて $\beta$ をパラメーターとし てとと申の関係を整理したものである。3D効果に及ぼ す $\beta$ の影響は $\phi$ 範囲によって著しく異なることがわ かる.すなわち， $\phi$ が十分小さい粘性土斜面では急斜面

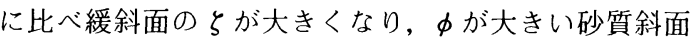
では逆に，急斜面のとがわずかながら大きくなってい る.このような傾向は円筒すべりを用いた鵜飼ら ${ }^{81}$ の計 算結果にも認められる.ただし, 円筒の回転軸方向に作 用する側方拘束力（鵜飼らは $x$ なる係数によって評価 している）を考えた場合に本解析結果と同様の特性が顕
著になっている. 鵜飼らの円筒（+キャップ）すべりの 解析では，その回転軸と直交する方向に土塊が滑動する と考えている.すなわち, 滑動方向 $m$ は, すべり面の 最大傾斜方向 $s$ と一致し, かつ常に一定である.しかし， 側方拘束力を導入することによって, 最大せん断力は滑 動方向に作用しない, 換言すれば最大せん断力 $\boldsymbol{t}$ の作 用方向が $s$ と一致しない場合を評価できるもので, 円 筒面を用いながら前章で述べた $3 \mathrm{D}$ すべり効果を評価し ていることになる. 一方, 本解析では滑動方向 $m$ と最 大せん断力 $\boldsymbol{t}$ の作用方向は同じで, $\boldsymbol{t}$ と $s$ はつり合い 条件から構成される汎関数の停留条件のもとに決定され る $^{5}$. すべり面を規定する方向 $s$ はすべり面上の各点で 異なり，また斜面特性によっても異なる， $\boldsymbol{t}$ の方向（m と同じ）が $s$ と一致する点もあれば一致しない点もあ る. $s$ と $\boldsymbol{t}$ の方向が一致しない場合を考慮できる点で は本解析は，側方拘束力を導入した鵜飼らの解析と同じ であるが， $m$ および $s$ が一致し，かつ一定 $(X$ 軸方向 $)$ であるか否かの点では異なっている。

Fig. 4 には, Fig. 2 の二例に対するすべり面を鳥瞰図 と平面図で示した。平面図に記した長い矢印は最大せん 断力 $\boldsymbol{t}$ の作用方向（矢印の長さは $\boldsymbol{t}$ の大きさを表わし ていない）を，短い矢印はコンターに直交する最大傾斜 方向 $s$ を表わす. $\boldsymbol{t}$ と $s$ のなす角を $\alpha$ とすると $\phi$ が小 さい緩斜面では $\alpha$ が大きくなる領域が多いのに対し $\phi$ の大きい急斜面ではすべり面周辺を除き比較的 $\alpha$ は小 さくすべり面も円筒に近くなる.ただし，Fig. 4 ですべ

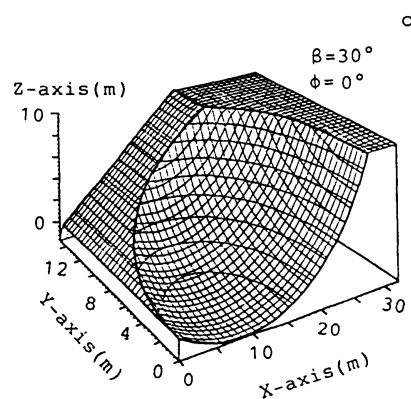

$\mathrm{C} / \mathrm{\gamma H}=0.1$
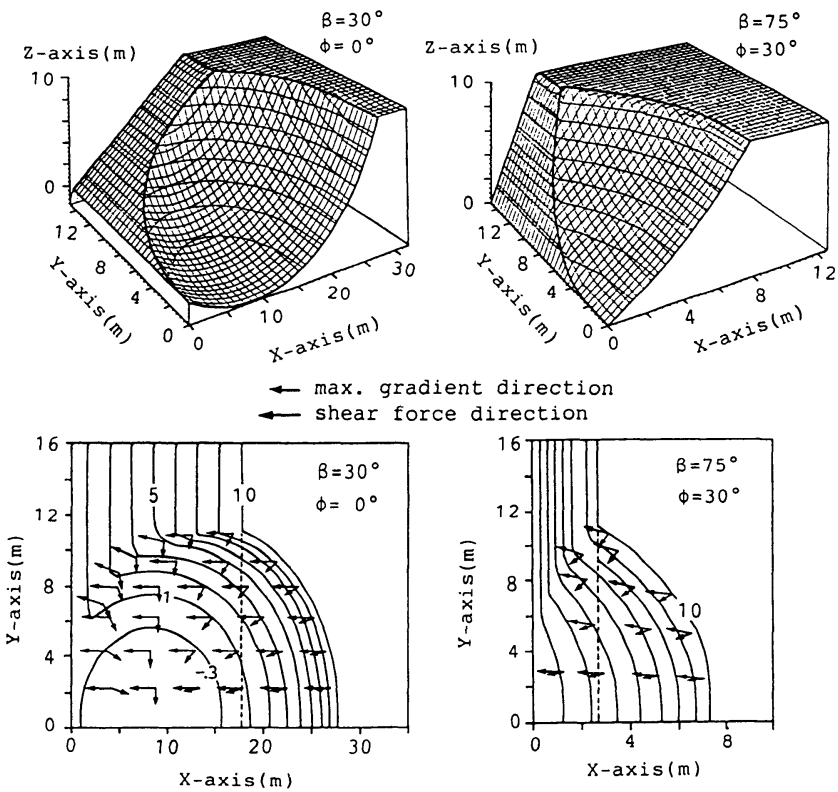

Fig. 4 Bird-eye view and plan view of slip surfaces. 
り面上各点で描いた 2 種類の矢印がなす角は $\alpha$ そのも のではなく $\alpha$ を水平面に射影した角である. また，計 算では 1500 以上の離散点で $s$ や $\boldsymbol{t}$ を求めている.

いま,すべり面上の微小領域 $d A=d X \times d Y$ を考える. その面に作用するせん断抵抗力 $\boldsymbol{t}_{\boldsymbol{j}}$ は法線方向の応力 (直 応力）上強度定数によって決まり， $d A$ 面で一定の大き さをもつ.ところがそこに作用する滑動力は土塊に作用 する重力の滑動方向 $m(\boldsymbol{t}$ の方向と同じ $)$ への分力で ある． $d A$ を底面とする土柱が, そこでの最大傾斜方向 $s_{j}$ へ滑動する場合の滑動力を $p_{2 j}$ とすると安全率は

$$
f_{2}=\int\left|\boldsymbol{t}_{j}\right| / p_{2 j} d A
$$

となる．ただし $\left|\boldsymbol{t}_{\boldsymbol{j}}\right|$ は $\boldsymbol{t}_{\boldsymbol{j}}$ の大きさである.このように $s_{j}$ と $\boldsymbol{t}_{j}$ の方向が常に一致すると考えるのが二次元解析 の立場である. しかし三次元では一般に $s_{j}$ と $\boldsymbol{t}_{j}$ の方向 は一致せず両者のなす角を $\alpha_{j}$ とすると滑動力 $p_{3 j}=p_{2 j}$ $\cos \alpha_{j}$ より本来の三次元安全率は次式となる.

$$
f_{3}=\int\left|\boldsymbol{t}_{j}\right| / p_{3 j} d A=\int\left|\boldsymbol{t}_{j}\right| /\left(p_{2 j} \cos \alpha_{j}\right) d A
$$

Table 1 や Fig. 3 で用いた安全率比 $\zeta$ は, $3 \mathrm{D}$ 解析の 安全率 $F_{3}$ よ $Y=L$ 面での $2 \mathrm{D}$ 解析の安全率 $F_{2}$ の比で ある. $3 \mathrm{D}$ 効果を評価するための汎用パラメーターとに 対して新たに無次元パラメーター

$$
\xi=f_{3} / f_{2}=\frac{\int\left|\boldsymbol{t}_{j}\right| /\left(p_{2, j} \cos \alpha_{j}\right) d A}{\int\left|\boldsymbol{t}_{j}\right| / p_{2 j} d A}
$$

乡は，3D解析で得られたすべり面を対象に，すべり面 の傾斜特性 $s$ やせん断力 $\boldsymbol{t}$ の作用方向 (=滑動方向) に関するデー夕を二次元解析的（ $\boldsymbol{t}$ の方向を $s$ と一致 させるという意味で）に用いた場合の安全率によって $3 \mathrm{D}$ の安全率を評価したものといえる. $\xi$ 関係を示 すFig. 5 によれば， $\xi$ は $\beta$ が大きいと $\phi$ に依存せず值 も低い。これは滑動方向 $m$ とすべり面の最大傾斜方向

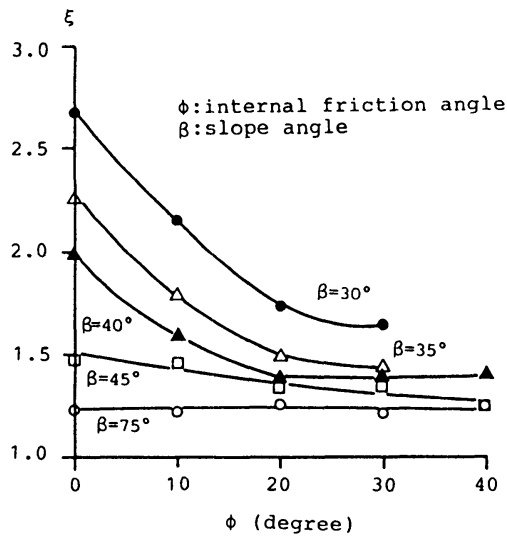

Fig. $5 \xi \sim \phi$ relation. $s$ が一致する円筒型に近いすべりが主となるためであ る. Fig. 2 右図からもわかるようにすべり面が二次元の 場合に近くなっている. Fig. 3 で $\beta=75^{\circ}$ 斜面が示す $\phi$ 依存の $3 \mathrm{D}$ 効果は主に端部効果によると考える. 一方, $\beta$ が小さいと $\xi$ は $\phi$ 強く依存し，かつ大きい值をと る. Fig. 4 左下図からも予想されるようにすべり面がす り鉢形となり2.で述べた $3 \mathrm{D}$ すべり効果が端部効果以 上に $3 \mathrm{D}$ 効果を引き起こしていると思われる. $\beta=30^{\circ}$, $\phi<10^{\circ}$ での Fig. 5 の $\xi$ 特性が, Fig. 3 の $\beta=30^{\circ}, \phi<$ $10^{\circ}$ におけるとの急大と強く関連しているはずである.

\section{4. 結 論}

（1）三次元解析による安全率が二次元解析のそれよ り大きくなる $3 \mathrm{D}$ 効果を生じる要因として, (1)端面抵抗 に起因する端部効果と(2)滑動方向がすべり面の最大傾斜 方向と一致しないことによる効果の 2 つが考えられる。

（2）内部摩擦角 $\phi>10^{\circ}$ ではすべり面が円筒形にな り $3 \mathrm{D}$ 効果は主に(1)によって生じる.そして, 急斜面の 方が緩斜面よりわずかながら $3 \mathrm{D}$ 効果が大となる.とこ ろが， $\phi<10^{\circ}$ では円筒に付加するキャップだけを考え たようなすり鉢形すべりとなるため(2)の効果が強く，特 に緩斜面での $3 \mathrm{D}$ 効果が急激に大きくなる (Fig. 3).

（３） фが小さい緩斜面を円筒形すべり面で解析する 場合側方拘束圧を導入する等の配慮が必要亡考える.

\section{参 考 文 献}

1) Baligh, M. M. and Azzouz, A. S. : End effects on stability of cohesive slopes, J. Geotech. Eng. Div., ASCE, 101, GT11, pp. 1105 1117, 1975.

2) Chen, R. H. and Chameau, J.-L. : Three-dimensional limit equilibrium analysis of slopes, Géotechnique 32 , No. 1, pp. 31 40, 1982

3) Gens, A., Hutchinson, J.N. and Cavounidis, S. : Three-dimensional analysis of slides in cohesive soils, Géotechnique, Vol. 38, No.1, pp. 1 23, 1988.

4) Hovland, H. J. : Three-dimensional slope stability analysis method, J. Geotech. Eng. Div., ASCE, 103, GT9, pp. 971 986, 1976.

5) Leshchinsky, D., Baker, R. and Silver, M. L. : Three dimensional analysis of slope stability, Int. j. num. anal. methods geom., 9, pp. 199 223, 1985.

6) Leshchinsky, D. and Baker, R. : Three-dimensional slope stability-End effects, Soils and Foundations, Vol. 26, No. 4, pp. $98 \sim 110,1987$

7) Ugai, K. : Three-dimensional stability analysis of ver tical cohesive slopes, Soils and Foundations, Vol.25, No. 3, pp. 41 48, 1985.

8）鵜飼恵三・細堀健司 - 永瀬英生 - 榎戸源則：簡便分割法 による斜面の三次元安定解析, 上木学会論文集, 第 376 号 /III-6, pp. 267 276, 1986.

(1989.4.10・受付) 